\title{
Comparação de métodos para monitorar populações de Alphitobius diaperinus (PANZER, 1797) (Coleoptera: Tenebrionidae) em granja avícola, em Pelotas, RS, Brasil
}

\author{
Comparison of methods to monitor populations of Alphitobius \\ diaperinus (PANZER, 1797) (Coleoptera: Tenebrionidae) in poultry \\ farm, Pelotas, RS, Brazil
}

Diego Moscarelli Pinto ${ }^{1}$; Paulo Bretanha Ribeiro²; Paulo Silveira Júnior ${ }^{2}$

\section{Resumo}

Alphitobius diaperinus (Panzer, 1797) (Coleoptera: Tenebrionidae) coloniza o substrato encontrado em granjas, criando-se em altas populações, causando problemas sanitários com reflexos econômicos. Neste trabalho foi realizada a avaliação comparativa de métodos de monitoramento de $A$. diaperinus. As avaliações foram feitas em um período de doze meses, em galpão de poedeiras do Conjunto Agrotécnico Visconde da Graça, em Pelotas - RS, Brasil, utilizando armadilhas do tipo "tubo" ou de Arends e tipo "sanduíche". A armadilha do tipo sanduíche mostrou-se mais eficiente na captura de larvas e adultos de A. diaperinus.

Palavras-chave: Cascudinho, monitoramento, armadilhas, avicultura

\begin{abstract}
Alphitobius diaperinus (PANZER, 1797) (Coleoptera: Tenebrionidae) it colonizes the substratum found at farms, growing up in high populations, causing sanitary problems with economical reflexes. In this work the comparative evaluation of monitoring methods was accomplished of $A$. diaperinus. The evaluations were made in a period of twelve months, in broiler barn of the Conjunto Agrotécnico Visconde da Graça, in Pelotas - RS, Brazil, using traps of the type "tube" or of Arends and type "sandwich". The type sandwich trap was shown more efficient in the capture of larvae and adults of $A$. diaperinus.
\end{abstract}

Key words: Lesser mearlworm, monitoring, traps, aviculture

${ }^{1}$ Departamento de Microbiologia e Parasitologia, Universidade Federal de Pelotas, Pelotas, RS, Brasil. E-mail: dimoscarelli@ yahoo.com.br.

2 Departamento de Microbiologia e Parasitologia, Universidade Federal de Pelotas, Pelotas, RS, Brasil.

* Autor para correspondência 


\section{Introdução}

Alphitobius diaperinus (PANZER, 1797) (Coleoptera: Tenebrionidae) também conhecido como cascudinho ou "lesser mearlworm", é uma praga de distribuição cosmopolita, sendo comumente encontrado em farinha e grãos armazenados (SAFRIT; AXTELL, 1984). Entretanto, possui maior importância em criações de aves domésticas, destinadas à corte, devido ao sistema de criação utilizado (aves no piso), onde o piso é revestido por cepilho (maravalhas), que misturado a fezes, ração excedente e água, tornam o ambiente propício ao desenvolvimento deste inseto (BRUNO et al., 1993).

Altas populações deste besouro em aviários são de grande importância devido ao potencial dos insetos de abrigar patógenos como vírus, bactérias, fungos, protozoários e nematódeos que causam doenças como Gumboro, Marek, Aspergilose e Coccidiose aviária, entre outras que afetam às criações de aves (EIDSON et al., 1965, 1966; DE LAS CASAS; POMEROY; HAREIN, 1968; DE LAS CASAS et al., 1973, 1976). Também abrem túneis no isolamento das construções causando perda de calor e gastos devido à necessidade de recolocação do isolamento (ICHINOSE; SHIBAZAKI; OHTA, 1980; PFEIFFER, 1978). Isolamentos com poliuretano e poliestireno podem ser altamente prejudicados pelos túneis fabricados principalmente pelas larvas (ICHINOSE; SHIBAZAKI; OHTA, 1980).

O controle de besouros em aviários tem sido impedido pela ausência de um método quantitativo que seja prático para amostragem da população. Métodos cansativos de contagem e índices grosseiros têm sido usados (HARDING JÚNIOR; BISSEL, 1958; SIMCO; EVERETT; LANCASTER, 1967). Entretanto, o monitoramento das populações de insetos é um procedimento que deve ser adotado dentro do programa de manejo, independente da estratégia utilizada para o controle (HICKLE, 1997; CHERNAKI-LEFFER et al., 2001).

Avaliações de métodos de amostragem de $A$. diaperinus em criações de perus e frangos sugerem que o tubo de Arends seja usado como um método de monitoramento de rotina e se mostrou eficiente na captura de coleópteros para avaliação da ocorrência e flutuação populacional (SAFRIT; AXTELL, 1984; BICHO et al., 2005).

Este trabalho visa comparar dois métodos de monitoramento de populações de $A$. diaperinus, através da utilização de armadilhas, tipo "tubo" ou de "Arends" e tipo "sanduíche".

\section{Material e métodos}

O experimento foi realizado durante 12 meses, no período de abril de 2002 a março de 2003, usando armadilhas do tipo "tubo" e tipo "sanduíche". As armadilhas foram expostas em galpão de poedeiras (criadas no sistema de cama), no Conjunto Agrotécnico Visconde da Graça (CAVG), pertencente à Universidade Federal de Pelotas, em Pelotas, RS. A fase de campo foi realizada no galpão de poedeiras em cama com maravalhas, sendo o lote de 1.200 galinhas da linhagem "Isa Brown".

Foram utilizados dois tipos de armadilhas, conforme descrito abaixo:

Armadilha do tipo "tubo" ou de Arends (SAFRIT; AXTELL, 1984) - consiste em um tubo de polivinilcloreto (PVC) de 3,8 cm de diâmetro por 23 $\mathrm{cm}$ de comprimento, contendo em seu interior papel corrugado, colocado de forma que as ondulações fiquem dispostas em sentido longitudinal ao tubo.

Armadilha do tipo "sanduíche" - similar a utilizada por Safrit e Axtell (1984), consiste em caixas de madeira de $20 \mathrm{~cm}$ de comprimento por 15 $\mathrm{cm}$ de largura e $8 \mathrm{~cm}$ de altura, com tampa e duas aberturas de $1 \mathrm{~cm}$ no sentido longitudinal, junto a base da caixa, para facilitar a entrada do coleóptero. No interior das armadilhas foi colocado papel corrugado, de modo a preencher a caixa.

Foram instaladas 16 armadilhas, aleatoriamente, em grupos de quatro, em quatro locais diferentes 
do galpão, equidistantes $30 \mathrm{~cm}$. Cada grupo estava composto por duas armadilhas do tipo "sanduíche" e duas armadilhas do tipo "tubo".

A cada sete dias, os insetos foram retirados das armadilhas e colocados em potes devidamente identificados, através de um funil de metal. Os papéis corrugados das armadilhas foram, semanalmente, substituídos por papéis novos e os insetos capturados foram levados ao laboratório para triagem, identificação e quantificação, sendo posteriormente depositados na coleção de insetos do laboratório de Biologia de Inseto - DEMP - IB - UFPEL . Os resultados obtidos foram submetidos a analise de variação, ao teste Duncan, utilizandose o programa estatístico SANEST (ZONTA; MACHADO, 1984).

\section{Resultados e discussão}

Durante o período experimental foram capturados 41.027 larvas e adultos de A. diaperinus (Tabela 1). Constatando-se na comparação dos métodos de amostragem que existe uma diferença em relação à freqüência de larvas e adultos coletados. Nas coletas realizadas utilizando-se as armadilhas do tipo sanduíche, foram capturados 39.692 espécimens, enquanto que nas coletas onde foram utilizadas as armadilhas do tipo tubo, foram capturadas 1.335 espécimens; portanto, a armadilha do tipo sanduíche capturou 96,75\% do total de larvas e adultos. Essa tabela, também demonstra que a armadilha sanduíche foi mais eficiente que a tubo, quando comparados isoladamente a captura de larvas e de adultos do cascudinho.

A armadilha tipo sanduíche apresentou maior média de captura de larvas e adultos que a armadilha tipo tubo (Tabela 2).

Tabela 1. Freqüência de larvas e adultos, de Alphitobius diaperinus, capturados, através de diferentes métodos de coleta, em galpão de aves poedeiras, no período de abril de 2002 a março de 2003, em Pelotas - RS.

\begin{tabular}{ccccc}
\hline \multirow{3}{*}{ Métodos } & \multicolumn{2}{c}{ Larvas } & \multicolumn{3}{c}{ Adultos } \\
\cline { 2 - 5 } & $\begin{array}{c}\text { Frequência absoluta } \\
\left(\mathrm{n}^{\mathbf{0}}\right)\end{array}$ & $\begin{array}{c}\text { Frequência relativa } \\
(\%)\end{array}$ & $\begin{array}{c}\text { Frequência absoluta } \\
\left(\mathrm{n}^{\mathbf{0}}\right)\end{array}$ & $\begin{array}{c}\text { Frequência relativa } \\
(\%)\end{array}$ \\
\hline Armadilha sanduíche & 985 & 90,34 & 38.707 & 96,92 \\
Armadilha tubo & 106 & 9,66 & 1229 & 3,08 \\
\hline Total & 1.091 & 100,00 & 39.936 & 100,00 \\
\hline
\end{tabular}

Tabela 2. Comparação de captura de larvas e adultos de Alphitobius diaperinus, em armadilhas "sanduíche" e "tubo de Arends", em Pelotas - RS.

\begin{tabular}{lccc}
\hline & \multicolumn{2}{c}{ Média de espécimens capturados } & \\
\multicolumn{1}{c}{ Métodos } & Larvas & Adultos & Teste de Duncan a 1\% \\
\hline Armadilha Sanduíche & 6,22 & 189,67 & A \\
\hline Armadilha Tubo & 0.67 & 5,56 & B \\
\hline
\end{tabular}

Vários autores ao compararem diferentes métodos para captura de $A$. diaperinus em galpões de criação de aves domésticas, concluíram que a armadilha do tipo tubo ou Arends é o método mais eficiente para monitoramento de rotina desses coleópteros, quando comparadas com fezes de galinhas em diferentes estágios de decomposição e armadilhas de solo "Pitfall trap" adaptadas de Walker (1985), que consiste de frascos de vidro com abertura de seis centímetros de diâmetro e 7,5 centímetros de 
altura, contendo no interior de cada frasco $200 \mathrm{ml}$ de fixador sugerido por Walker (1985), composto de água destilada, detergente, formol e álcool 70\% (SAFRIT; AXTELL, 1984; FRANCISCO, 1996; BICHO et al., 2005).

A facilidade de manejo na utilização de armadilhas para captura de cascudinhos, seguindo o modelo de Arends tem sido comprovada pela literatura(SAFRIT;AXTELL, 1984; STRINGHAM; ARENDS, 2000; STRINGHAM, 2000; SILVA et al., 2001).

Porém, neste trabalho, ao comparar dois métodos para monitoramento de A. diaperinus ao longo de doze meses, constatou-se que a armadilha do tipo sanduíche proporcionou o melhor resultado, tanto no que se refere à captura de larvas como para a captura de adultos, quando comparada com a armadilha tipo tubo ou Arends, provavelmente devido ao material utilizado na confecção da armadilha sanduíche.

\section{Conclusões}

A armadilha do tipo sanduíche foi mais eficiente que a armadilha tipo tubo ou Arends, tanto na captura de adultos como na de larvas de A. diaperinus, sendo que ambas são mais eficientes para captura de adultos do que larvas.

\section{Referências}

BICHO, C. L.; ALMEIDA, L. M.; RIBEIRO, P. B.; SILVEIRA JÚNIOR, P. S. Flutuação populacional de coleópteros em granja avícola, em Pelotas, RS, Brasil. Iheringia, Porto Alegre, v. 95, n. 2, p. 205-212, 2005.

BRUNO, T. V.; GUIMARÃES, J. H.; SANTOS, Â. M.; TUCCI, E. C. Moscas sinantrópicas (Díptera) e seus predadores que se criam em esterco de aves poedeiras confinadas, no estado de São Paulo, Brasil. Revista Brasileira de Entomologia, São Paulo, v. 37, n. 3, p. 577 590, 1993.

CHERNAKI-LEFFER, A. M. C.; LAZZARI, F. A.; LAZZARI, S. M. N.; ALMEIDA, L. M. Controle do cascudinho. Revista Avicultura Industrial, São Paulo, v. 92, n. 1094, p. 22-25, 2001.
DE LAS CASAS, E.; HAREIN, P. K.; DESHMUKH, D. R.; POMEROY, B. S. Relationship between the lesser mealworm, fowl pox, and Newcastle disease virus in poultry. Journal of Economic Entomology, College Park, v. 69 , n. 6 , p. $775-779,1976$.

The relationship beween the lesser Mealworm and avian viruses. 1. Reovirus 24. Environmental Entomology, College Park, v. 2, n. 6, p. 1043-1047, 1973.

DE LAS CASAS, E.; POMEROY, B. S.; HAREIN, P. K. Infection and quantitative recovery of Salmonella typhimurium and Escherichia coli from within the lesserMealworm (Alphitobius diaperinus). Poultry Science, Champaign, v. 47, n. 6, p. 1871-1875, 1968.

EIDSON, C. S.; SCHMITTLE, S. C.; LAL, J. B.; GOODE, R. B. Induction of leucosis tumors with the beetle Alphitobius diaperinus. American Journal Veterinary Research, Chicago, v. 27, n. 119, p. 10531057, 1966.

. The role of darkling beetle, Alphitobius diaperinus in transmission of acute leucosis in chickens. Poultry Science, Champaign, v. 44, p. 1366-1367, 1965.

FRANCISCO, O. Alphitobius diaperinus (Panzer) (Coleoptera: Tenebrionidae) associado a esterco em granjas de aves poedeiras: fenologia, estrutura etária e parasitismo. 1996. Dissertação (Mestrado em Entomologia) - Universidade Estadual de Campinas, Campinas.

HARDING JÚNIOR, W. C.; BISSEL, T. L. Lesser mealworm in a brooder house. Journal of Economic Entomology, College Park, v. 51, n. 1, p. 112, 1958.

HICKLE, L. A. Integrated pest management in poultry houses. Poultry Digest, Mount Morris, v. 56, n. 1, p. 1-23, 1997.

ICHINOSE, T.; SHIBAZAKI, S.; OHTA, M. Studies on the biology and mode of infestation of the Tenebrionid beetle Alphitobius diaperinus (Panzer) harmful to broilerchicken houses. Japanese Journal Applied Entomology Zoology, Japan, v. 24, n. 3, p. 167-174, 1980.

PFEIFFER, D. G. The Coleoptera of poultry houses in North Carolina. 1978. Thesis (Master of Science) North Carolina State University, Raleigh. CONFIRMAR INFORMAÇÃO EM DESTAQUE

SAFRIT, R. D.; AXTELL, R. C. Evaluations of sampling methods for darkling beetles (Alphitobius diaperinus) in the litter of turkey and broiler houses. Poultry Science, Champaign, v. 63, n. 12, p. 2368-2375, 1984. 
SILVA, G. F.; VERONEZ, V. A.; OLIVEIRA, G. P.; BORGES, F. A.; SILVA, H. C.; MEIRELES, M. V. Avaliação de métodos de amostragem de "Cascudinhos" Alphitobius diaperinus (Panzer) (Coleoptera: Tenebrionidae) em cama de frangos de corte. Semina: Ciências Agrárias, Londrina, v. 22, n. 1, p. 73-76, 2001.

SIMCO, J. S.; EVERETT, R.; LANCASTER, J. L. Preliminary studies on control of lesser mealworm in broiler houses. Arkansas Farm Research, Fayetteville, v. 15, n. 6, p. 8, 1967.

STRINGHAM, M.; ARENDS J. J. Evaliation of a modified Arends tube trap for sampling the lesser mealworm, Alphitobius diaperinus (Panzer), in turkey brooder houses [mensagem pessoal]. Mensagem recebida por<serafim@fcav.unesp.br>em 8 dez. 2000.

STRINGHAM, S. M. Comparison of standard and modified tube traps for sampling darkling beetles, Alphitobius diaperinus (Panzer), in broiler houses [mensagem pessoal]. Mensagem recebida por $<$ serafim@ fcav.unesp.br> em 08 dez. 2000.

WALKER, M. A. A Pitfall trap study on Carabidae and Staphylinidae (Col.) in County Durham. Entomologist's Monthly Magazine, Oxford, v. 121, n. 1, p. 9-18, 1985.

ZONTA, E. P.; MACHADO, A. A. SANEST - Sistema de Análise Estatística para Microcomputadores. Registrado na Secretaria Especial de Informática sob nº.066060 categoria A. Pelotas: Ed. da UFPel, 1984. 
